\title{
Do children's intentions to risk take relate to actual risk taking?
}

\section{B A Morrongiello}

See end of article for authors' affiliations .....................

Correspondence to: Dr Barbara A Morrongiello, Psychology Department, University of Guelph, Guelph, Ontario Canada N1G 2W1; bmorrong@uoguelph.ca
Objectives: Concerns about safety and rigorous ethic standards can make it very difficult to study children's risk taking. The goal of this study was to determine how closely intentions to risk take relate to actual risk taking among boys and girls 6-11 years of age.

Methods: Children initially completed an "intentions to risk take" task. Following administration of several questionnaires they later participated in an actual risk taking task.

Results: At all ages, for both boys and girls, intentions to risk take was highly positively correlated with actual risk taking. When discrepancies occurred these were usually of minimal magnitude.

Conclusions: Tasks that tap children's intentions to risk take can serve as proxy indicators of children's actual risk taking.
U nintentional injuries are the leading cause of death for children beyond 2 years of age. ${ }^{12}$ During the preschool years, most injuries occur in and around the home. ${ }^{3}$ Because decisions made by caregivers can contribute to young children's risk of home injury, ${ }^{4}{ }^{5}$ studies of injury risk during the preschool period often focus on measuring caregivers' attitudes and behaviors. ${ }^{6-9}$ For school age children, however, the majority of injuries occur when they are away from the home and left to make decisions for themselves about risk taking. ${ }^{3}$ Hence, studies of injury risk among school age children often focus on measuring children's attitudes and behaviors. ${ }^{10-13}$

One of the biggest challenges in studies of injury risk among school age children is to measure children's risk taking in ways that are ecologically valid but do not actually place the child at risk of injury. Often, intentions to risk take (that is, expressed willingness to engage in injury risk behaviors), rather than actual risk taking, are measured. There is evidence that children's self reports about risk taking correlate with teacher, parent, and peer ratings, as well as with their injury history. ${ }^{14}$ These findings suggest that children are reliable reporters about their typical level of risk taking and can provide valid self reports of their willingness to risk take. We know of no studies, however, that have directly examined whether intentions to risk take reported by children in a non-risk situation are valid indicators of what children actually would do in injury-risk situations. As part of a larger study on the determinants of children's actual risk taking, we addressed this important validity question.

\section{METHODS \\ Sample}

The sample comprised 131 children who were recruited from local schools and categorized into three age groups: young ( 6 and 7 years old; 25 boys and 18 girls), intermediate ( 8 and 9 years old; 23 boys and 19 girls), old ( 10 and 11 years old; 24 boys and 22 girls); schools were strategically sampled to provide a broad representation of income levels as indexed by the types and cost of housing nearby the schools. All children were English speaking, in regular classes, and had never been hospitalized for an injury.

\section{Measures}

All methods were reviewed and independently approved by the Ethics Review Committees at the University of Guelph and the Upper Grand District school board. Children completed an "intentions to risk take" task in which they were asked to indicate how high they would place a balance beam from the floor to walk across the beam on their own. To aid in these judgments children were shown a ruler drawn on the wall with markers indicated at each foot interval (1-8 feet); they stood facing this ruler so they could fully appreciate their own height relative to the heights indicated on the wall. They were also shown photos of what it would look like if they were standing on the beam looking down to the floor, with the beam positioned at different heights (that is, foot intervals, starting with 1 and continuing through 8 ). Children examined these two sources of information and then made their judgment regarding the greatest height at which they would place the beam to walk across. Subsequently, they completed a variety of questionnaires (for example, personality measures) and then completed the actual balance beam task in which they decided on the height of the beam and independently walked across the beam. It should be noted that a variety of safety measures were taken to ensure that none of the children experienced any injuries while walking the balance beam: gymnastics mats were placed on the floor and the research assistant who stood nearby was actually a gymnastics coach trained in how to interrupt falls from balance beams to prevent serious injury; no child was injured completing this task.

\section{RESULTS}

The risk taking scores obtained for the intentions to risk take and actual risk taking tasks are shown in table 1, along with the difference between these scores (that is, intentions score minus actual score). As can be seen, the difference scores were relatively low. In fact, the percentage of judgments by children at each age that were exact matches between intentions to risk take and actual risk taking and minimal mismatches is shown in table 2 (that is, one unit, that is 1 foot, discrepancy between children's intentions to risk take and actual risk taking). As can be seen in table 2, for boys and girls at all ages there was generally very good correspondence between intentions to risk take and actual risk taking, particularly at the intermediate and older ages. Moreover, 
Table 1 Average scores (possible range 1.00-8.00, higher numbers indicate greater risk taking) for males $(M)$ and females $(F)$ in the young ( 6 and 7 year olds), intermediate (8 and 9 year olds), and old (10 and 11 year olds) age groups for the intentions to risk take and actual risk taking tasks. The difference score was computed as intentions minus actual score (95\% confidence interval is given in parentheses)

\begin{tabular}{lllllr}
\hline Group & No & Sex & Intentions to risk take & Actual risk taking & \multicolumn{1}{l}{ Difference score } \\
\hline Young & 25 & $M$ & $6.28(5.45$ to 7.11$)$ & $6.16(5.46$ to 6.86$)$ & $0.12(-0.46$ to 0.70$)$ \\
& 18 & $\mathrm{~F}$ & $6.44(5.60$ to 7.28$)$ & $6.28(5.46$ to 7.09$)$ & $0.16(-0.45$ to 0.79$)$ \\
Intermediate & 43 & $M+F$ & $6.35(5.78$ to 6.92$)$ & $6.21(5.70$ to 6.72$)$ & $0.14(-0.27$ to 0.55$)$ \\
& 23 & $M$ & $5.78(4.97$ to 6.60$)$ & $5.91(5.10$ to 6.73$)$ & $-0.13(-0.48$ to 0.22$)$ \\
Old & 19 & $\mathrm{~F}$ & $5.84(4.92$ to 6.77$)$ & $5.79(4.83$ to 6.75$)$ & $0.05(-0.06$ to 0.16$)$ \\
& 42 & $M+F$ & $5.81(5.22$ to 6.39$)$ & $5.86(5.26$ to 6.45$)$ & $-0.05(-0.24$ to 0.15$)$ \\
& 24 & $M$ & $6.92(6.38$ to 7.46$)$ & $6.92(6.38$ to 7.46$)$ & $0.00(-0.35$ to 0.35$)$ \\
Overall & 22 & $F$ & $5.91(5.33$ to 6.49$)$ & $6.23(5.59$ to 6.87$)$ & $-0.32(-0.76$ to 0.12$)$ \\
& 46 & $M+F$ & $6.43(6.03$ to 6.84$)$ & $6.59(6.17$ to 7.00$)$ & $-0.16(-0.42$ to 0.12$)$ \\
& 72 & $M$ & $6.33(5.91$ to 6.75$)$ & $6.33(5.94$ to 6.73$)$ & $0.00(-0.25$ to 0.25$)$ \\
& 59 & $F$ & $6.05(5.63$ to 6.48$)$ & $6.10(5.66$ to 6.54$)$ & $-0.05(-0.29$ to 0.19$)$ \\
& 131 & $M+F$ & $6.21(5.91$ to 6.50$)$ & $6.23(5.94$ to 6.52$)$ & $-0.02(-0.20,0.15)$ \\
\hline
\end{tabular}

when mismatches occurred these were often minimal (one unit) differences, particularly at the intermediate and older ages.

Pearson product moment correlations confirmed (see table 3) that intentions to risk take were highly positively correlated with children's actual risk taking. Hence, the height at which children intended to place the beam coincided exactly with the height at which they actually placed the beam to walk across the majority of time. Moreover, combining exact matches with minimal mismatches resulted in even higher correlations (see table 3 ).

Examining the extent of discrepancy when intentions and actual risk taking scores differed provided further support for the conclusion that reports about intentions to engage in risk taking activities are good proxy indicators of actual risk taking. Specifically, we hypothesized that the magnitude of discrepancy between intentions to risk take and actual risk taking would be 0 or 1 (that is, as small as possible), rather than larger (that is, 2 or more). To test this hypothesis, we computed the DEL statistic based on comparing the two scores. ${ }^{15}$ The resulting DEL value of 0.73 indicates very good support for the model, and this is confirmed by a precision score of 0.78 (that is, the higher this value the more the obtained scores are consistent with what is predicted by the model, that is, the difference between intentions and actual risk taking will be 0 or 1 more often than 2 or greater) and $z=30.75, \mathrm{p}<0.001$; comparing difference scores to 0 also confirmed non-significant differences between intentions and actual risk taking scores ( $\mathrm{ps}>0.05$ ). Hence, the present findings indicate that intentions to risk take exactly, or very closely, approximate how children will actually behave in risk taking situations.

\section{DISCUSSION}

Prior research examining school age children's self reports about risk taking revealed that children are aware of their risk taking, can report on these behaviors, and their reports are valid in that they correspond to what both parents and teachers report. ${ }^{14}$ The present findings extend these results and demonstrate that children's intentions to risk take can serve as useful proxy measures for actual risk taking. For boys and girls in each age group, intentions to risk take were highly positively related to subsequent risk taking. Similar findings have been noted in research on adolescent health risk behaviors. ${ }^{16}$ However, to our knowledge, these are the first data to confirm the validity of intentions to risk take measures among school age children.

Applying a developmental perspective, it is apparent in tables 1 and 2 that children in the youngest group (6 and 7 years of age) showed the weakest relations between

Table 2 Percentage of judgments by males $(M)$ and females $(F)$ in the young $(6$ and 7 year olds), intermediate ( 8 and 9 year olds), and old ( 10 and 11 year olds) age groups that were exact matches between intentions to risk take and actual risk taking (that is, 0 discrepancy in scores) and minimal mismatches (that is, the discrepancy between the two scores was one unit) (95\% confidence interval is given in parentheses)

\begin{tabular}{|c|c|c|c|c|c|}
\hline Group & No & Sex & Exact matches & Minimal mismatches & $\begin{array}{l}\text { Exact }+ \text { minimal } \\
\text { mismatches }\end{array}$ \\
\hline \multirow[t]{3}{*}{ Young } & 25 & M & 72.0 (54.0 to 90.0$)$ & $4.0(-4.6$ to 12.4$)$ & $76.0(58.9$ to 93.1$)$ \\
\hline & 18 & $\mathrm{~F}$ & $66.7(45.1$ to 88.3$)$ & $16.7(-1.0,34.4)$ & 83.4 (65.7 to 101.1$)$ \\
\hline & 43 & $M+F$ & 69.8 (55.9 to 83.7$)$ & $9.4(0.6$ to 18.2$)$ & 79.2 (66.9 to 91.5$)$ \\
\hline \multirow[t]{3}{*}{ Intermediate } & 23 & M & $82.6(66.8$ to 98.4$)$ & $8.7(-3.1$ to 20.5$)$ & 91.3 (79.5 to 113.1$)$ \\
\hline & 19 & $\mathrm{~F}$ & 94.7 (84.4 to 105.0 ) & $5.3(-5.0$ to 15.6$)$ & 100.0 \\
\hline & 42 & $M+F$ & 88.1 (78.2 to 98.0$)$ & $7.1(-0.8$ to 15.0$)$ & 95.2 (88.7 to 101.7 ) \\
\hline \multirow[t]{3}{*}{ Old } & 24 & $M$ & $79.2(62.6$ to 95.8$)$ & 12.5 (1.0 to 26.0 ) & 91.7 (80.4 to 113.0$)$ \\
\hline & 22 & $\mathrm{~F}$ & 77.3 (59.4 to 95.2 ) & $13.6(1.1$ to 38.3$)$ & 90.9 (78.6 to 103.2$)$ \\
\hline & 46 & $M+F$ & $78.3(66.2$ to 90.4$)$ & 13.0 (3.2 to 22.8 ) & 91.3 (83.1 to 99.5 ) \\
\hline \multirow[t]{3}{*}{ Overall } & 72 & M & $77.8(68.1$ to 87.5$)$ & 8.4 (2.0 to 14.8 ) & 86.2 (78.2 to 94.2$)$ \\
\hline & 59 & $\mathrm{~F}$ & $79.7(69.3$ to 90.1$)$ & 11.9 (3.6 to 20.2 ) & 91.6 (84.4 to 98.8 ) \\
\hline & 131 & $M+F$ & 78.6 (71.5 to 85.7$)$ & 9.9 (4.7 to 15.1$)$ & 88.5 (83.0 to 94.0$)$ \\
\hline
\end{tabular}


Table 3 Correlations between intentions to risk take and actual risk taking scores for males $(M)$ and females $(F)$ in the young (6 and 7 year olds), intermediate (8 and 9 year olds), and old (10 and 11 year olds) age groups (95\% confidence interval is given in parentheses)

\begin{tabular}{lllll}
\hline Group & No & Sex & Exact matches* only & Exact + minimal mismatchest \\
\hline Young & 25 & $\mathrm{M}$ & $0.73(0.47$ to 0.87$)$ & $0.73(0.47$ to 0.87$)$ \\
& 18 & $\mathrm{~F}$ & $0.72(0.38$ to 0.89$)$ & $0.74(0.42$ to 0.90$)$ \\
Intermediate & 43 & $\mathrm{M}+\mathrm{F}$ & $0.73(0.55$ to 0.85$)$ & $0.73(0.55$ to 0.85$)$ \\
& 23 & $\mathrm{M}$ & $0.91(0.80$ to 0.96$)$ & $0.93(0.80$ to 0.96$)$ \\
Old & 19 & $\mathrm{~F}$ & $0.99(0.97$ to 1.00$)$ & 1.00 \\
& 42 & $\mathrm{M}+\mathrm{F}$ & $0.95(0.91$ to 0.97$)$ & $0.96(0.93$ to 0.98$)$ \\
& 24 & $\mathrm{M}$ & $0.79(0.57$ to 0.90$)$ & $0.83(0.64$ to 0.92$)$ \\
Overall & 22 & $\mathrm{~F}$ & $0.74(0.46$ to 0.89$)$ & $0.78(0.53$ to 0.90$)$ \\
& 46 & $\mathrm{M}+\mathrm{F}$ & $0.78(0.63$ to 0.87$)$ & $0.82(0.70$ to 0.90$)$ \\
& 72 & $\mathrm{M}$ & $0.82(0.73$ to 0.88$)$ & $0.86(0.78$ to 0.91$)$ \\
& 59 & $\mathrm{~F}$ & $0.84(0.74$ to 0.90$)$ & $0.84(0.74$ to 0.90$)$ \\
& 131 & $\mathrm{M}+\mathrm{F}$ & $0.83(0.77$ to 0.88$)$ & $0.85(0.79$ to 0.89$)$ \\
\hline
\end{tabular}

*Exact matches designates a 0 discrepancy between intentions and risk taking scores.

†Minimal mismatches designates a discrepancy of one unit of measurement.

\section{Key points}

- Children are aware of their risk taking behaviors and can report on these, as well as on their intentions to risk take.

- Children's reported intentions to risk take is closely aligned with how they actually behaved in risk situations.

- Investigators interested in studying risk taking without placing children at actual risk of injury can utilize intentions as proxy measures for risk taking.

intentions to and actual risk taking. Although the correspondence between these two scores is still fairly good, and the correlations highly significant, researchers may need to exercise more caution in interpreting children's intentions to risk take judgments at these young ages.

Of course, one limitation of the present study is that we examined the relation between intentions and actual risk taking for only one risk taking situation. Hence, the generalizability of the conclusions remains to be assessed. We would suggest, however, that if one can obtain such high correlations for a task with which most children had limited or no prior experience, there would probably be even greater, not less, correspondence between intentions and actual risk taking for situations with which children have more extensive prior experience (for example, playground, swimming pool). Hence, the present data may provide a conservative estimate of how close the correspondence is between measures of children's intentions and actual risk taking. Further research is needed to address this important issue.

In conclusion, the present results suggest that measures of intentions to risk take can be interpreted as valid indicators of how school age children are likely to behave in risk taking situations, particularly for children 8-11 years of age.

\section{ACKNOWLEDGEMENTS}

This research was funded by a grant from the Canadian Institutes of Health Research. The author extends her thanks to Kate House, Natalie Johnston, Sophie Kiriakou, Barb Kuczynski, Kathy Major, Hilary Newell, Meghan McCourt, and Joni Planetta for assistance with data collection; to Shawn Matheis for assistance with data analysis; and to the schools and children for their willingness to participate in this study.

\section{REFERENCES}

1 Baker SP, O'Neil B, Ginsburg M. The injury fact book. New York, NY: Oxford University Press, 1992.

2 Canadian Institute of Child Health. The health of Canada's children: a profile, 3rd Ed. Ottawa, Ontario: Canadian Institute of Child Health, 2000.

3 Shannon A, Brashaw B, Lewis J, et al. Nonfatal childhood injuries: a survey at the Children's Hospital of Eastern Ontario. CMAJ 1992;146:361-5.

4 Morrongiello BA, Dayler L. A community-based study of parents' knowledge, attitudes and beliefs related to childhood injuries. Can J Public Health 1996:87:383-8.

5 Eichelberger $\mathrm{M}$, Gotschall C, Feely $\mathrm{H}$, et al. Parental attitudes and knowledge of child safety. Am J Dis Child 1990;144:714-20.

6 Morrongiello BA, Ondejko L, Littlejohn A. Understanding toddlers' in home injuries: I. context, correlates, and determinants. J Pediatr Psychol (in press).

7 Morrongiello BA, Ondejko L, Littlejohn A. Understanding toddlers' in home injuries: II. examining parental strategies, and their efficacy, for moderating child injury risk. J Pediatr Psychol (in press).

8 Garling A, Garling T. Mothers' supervision and perception of young children's risk of unintentional injury in the home. J Pediatr Psychol 1993;18:105-14.

9 Garling A, Garling T. Mothers' anticipation and prevention of unintentional injury to young children in the home. J Pediatr Psychol 1995;20:23-36.

10 Jaquess D, Finney J. Previous injuries and behavior problems predict children's injuries. J Pediatr Psychol 1994;19:79-89.

11 Schwebel D, Plumert J. Longitudinal and concurrent relations among temperament, ability estimation, and injury proneness. Child Dev 1999;70:700-12.

12 Morrongiello B, Rennie H. Why do boys engage in more risk taking than girls? The role of attributions, beliefs, and risk appraisals. J Pediatr Psychol 1998;23:33-43.

13 Peterson L, Oliver K, Brazeal T, et al. A developmental exploration of expectations for and beliefs about preventing bicycle injuries. J Pediatr Psychol 1995;20:13-22.

14 Potts R, Martinez I, Dedmon A. Childhood risk taking and injury: self report and informant measures. J Pediatr Psychol 1995;20:5-12.

15 Hildebrand D, Lainge J, Rosenthal H. Prediction analysis of cross classifications. New York, NY: Wiley, 1977.

16 Gibbons F, Gerrard M. Predicting young adults' health risk behavior. Journal of Personality and Social Psychology 1995;69:505-17. 